

\section{"Uma festa baphônica no Twitter": narrativa de si e apropriação de linguagem nas construções identitárias da personagem Katylene e seu criador a partir do caso da hashtag \#KatyBDay}

\section{"One hell of a Twitter party": self narrative and appropriation of Katylene's language and it's creator as a case study of hashtag \#KatyBDay}

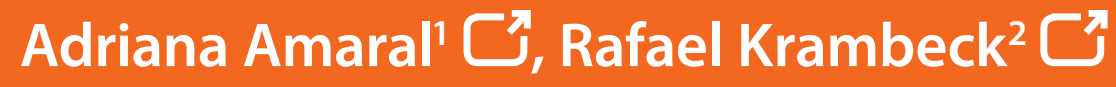

\section{Resumo}

O presente trabalho discute a temática das construções de narrativas identitárias a partir da análise do caso da personagem Katylene Beezmarcky e de seu criador, Daniel Carvalho, no Twitter. Para isso, busca-se construir um embasamento teórico em três vias que tentam dar conta sobre as construções de identidades nas redes, a potencial instauração de "celebridades da web" e a apropriação social de uma cultura e linguagem características veiculadas pela personagem no espaço digital. A análise focou-se em tweets publicados entre 28 de abril e 4 de maio de 2012 e, a partir da categorização dos mesmos, reflete sobre a relação estabelecida entre Katylene e Daniel e entre Katylene e seus seguidores.

\section{Palavras-chave}

Twitter; identidade; apropriação de linguagem nas redes sociais.

\section{Abstract}

This paper discusses the construction of self narratives on a specific case of study: Katylene Beezmarcky's Twitter, a character created on the internet and its creator, Daniel Carvalho. In order to discuss this we discussed three theoretical aspects: constructions of identites on cyberspace; the potential of webcelebrities and the social appropriation of an specific culture throught the character's specific language. We've analyzed tweets published between April 28th and May 4th of 2012 and from its categorization we discussed interaction relations among both Katylene and Daniel and their followers.

\section{Keywords}

Twitter; identity; language appropriation on social network. 


\section{Introdução e contextualização}

Fui aomilhada, passei por uma série de problemas e consegui dar a voltar por cima e moshtrar meu valor". Biografia de Katylene no blog. ${ }^{3}$

Salvo as grafias características das palavras "humiIhada" e "mostrar", essa curta biografia poderia pertencer à qualquer um que tenha uma história semelhante. Contudo, aos mais "antenados" aos assuntos populares no contexto brasileiro da internet, basta essa simples troca/inserção de letras para que se reconheçam traços da identidade de Katylene Beezmarcky ${ }^{4}$ no texto. A personagem travesti, criada inicialmente pela dupla de blogueiros Daniel Carvalho e Mariana Inbar, surgiu em substituição aos pseudônimos "Sônia Abraham" e "Angela Bismarchi" anteriormente utilizados para assinar o extinto blog Papel Pobre (paródia do blog "Papel Pop" de Phelipe Cruz, jornalista e editor do site da Revista Capricho), no qual ironizavam e cobriam o mundo das celebridades nacionais e internacionais.

Inicialmente, a personagem Katylene despertou curiosidade na comunidade de leitores e em outros blogueiros, pois Daniel e Mariana não se identificaram como os autores por trás do humor ácido do blog, porém, o anonimato durou pouco. Frente à grande popularização do blog em 2007, a jornalista Rosana Hermann lançou a pergunta "Quem seriam por trás de Katylene? ${ }^{6 "}$. Não demorou muito, a blogueira Adriana Spaca respondeu a essa pergunta "Nenhum segredo é grande o suficiente para ser guardado eternamente na internet ${ }^{7 \prime}$, disse ela em seu blog, onde linkou o perfil de Daniel no Orkut. Daniel, por sua vez, publicou a mesma foto no Papel Pobre com a legenda "Katy, é você?". $O$ retorno da personagem Katylene aconteceu apenas em outubro de 2008 quando Daniel Carvalho assumiu a autoria e o controle da personagem. A partir daí, o blog adotou o nome da personagem como endereço e título e já contava com mais de um milhão de acessos mensais e um perfil no Twitter, onde a personagem Katylene se autointitulava "Musa do Twitter". Nessa plataforma, até o momento da última coleta de dados? o perfil da personagem (@katylene) contava com mais de 240 mil seguidores, enquanto o perfil de Daniel (@ cadeodaniel) possuia, aproximadamente, 20 mil.

A inquietação que ocasionou este artigo tem origem na impressão de paralelismo entre as narrativas. Desta forma, observa-se o episódio decorrente do aniversário de Daniel em primeiro de maio de 2012 e seu desenvolvimento no Twitter. Para tal, inicialmente, propõe-se uma reflexão acerca das construções identitárias on-line, para, então, pensar na possível celebrização de figuras particulares da internet, tal qual Katylene e, assim, inserir a temática da importância da relação estabelecida entre público e personagem. Desta forma, espera-se responder questionamentos como "de que forma se dá a construção da/o Katylene/Daniel no Twitter?" e "como a personagem movimenta uma 'cultura' que, apropriada por seus seguidores, expande e legitima a experiência da mesma?".

\section{Rediscutindo a constituição}

\section{das identidades on-line}

Já em 1998, Kenway observava que, a partir da conexão pela internet, indivíduos podem constituir relações afetivo-sexuais que ignoram as dimensões temporais e espaciais, e ir além, estabelecendo diferentes formas de relacionar-se às questões de gênero e sexualidade. Segundo a autora, dois possíveis elementos da comunicação tecnologicamente mediada - o anonimato e a fácil troca de identidade - serão fundamentais para que jogos de identidades se estabeleçam e propiciem tais ex- perimentações. No entanto, se avaliarmos a consideração que Moore (2000) faz sobre os sujeitos inseridos em uma rede de discursos e práticas, onde eles "assumem uma variedade de posições de sujeito dentro de diferentes discursos", podemos pensar em "sujeitos multiplamente constituídos, e podem assim assumir múltiplas posições". Desse modo, podemos observar a construção da identidade on-line em dois aspectos fundamentais enumerados por Sá \& Polivanov:

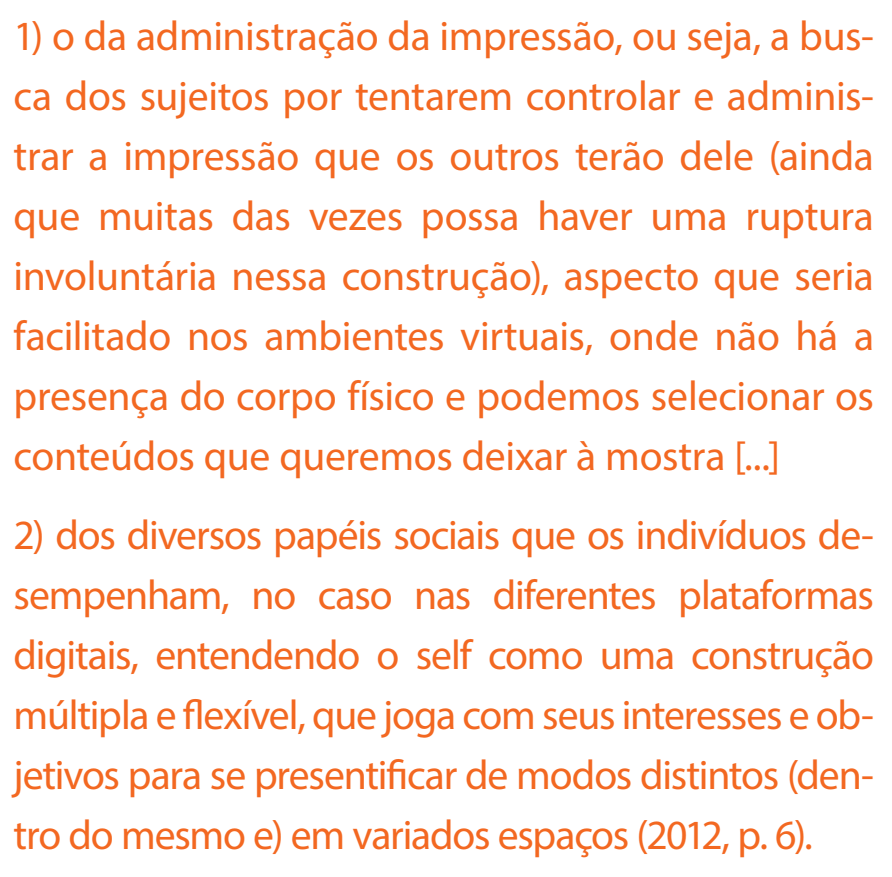
ca dos sujeitos por tentarem controlar e administrar a impressão que os outros terão dele (ainda que muitas das vezes possa haver uma ruptura involuntária nessa construção), aspecto que seria facilitado nos ambientes virtuais, onde não há a presença do corpo físico e podemos selecionar os conteúdos que queremos deixar à mostra [...]

2) dos diversos papéis sociais que os indivíduos desempenham, no caso nas diferentes plataformas digitais, entendendo o self como uma construção múltipla e flexível, que joga com seus interesses e objetivos para se presentificar de modos distintos (dentro do mesmo e) em variados espaços $(2012$, p. 6).

Para Sá \& Polivanov (2012) existem rastros de materialidades a partir desse gerenciamento de impressões nas fotografias, vídeos, links e outros conteúdos postados nos sites de redes sociais. Essas pistas materiais indicariam questões de gosto, de performatização que fazem parte da constituição das identidades e que se tornam visíveis nas postagens.

Neste estudo, interessa-nos pensar este processo de administração da impressão enquanto um proces- 
so autorreflexivo (Giddens, 2002) que permite a criação de "personagens de si", sejam eles uma tentativa de "espelhar" a realidade (tal qual o Twitter @cadeodaniel), ou "criar" uma realidade narrativa de um personagem (tal qual o Twitter @katylene). Schau e Gilly (2003) consideram que "livres das limitações materiais do corpo físico, da propriedade e da proximidade, esses novos modos de autoexpressão do consumidor revelam inovadoras estratégias de autoapresentação" (p. 386).

Em seu estudo sobre a construção de páginas pessoais na internet, Döring (2002) pondera que os conceitos "identidade cultural", "identidade narrativa", "self múltiplo" "self dinâmico" e "self dialógico" focalizam nas características de construção, mudança e diversidade de tais identidades. Contudo, tais características não são exclusivas dos ambientes on-line, e o trabaIho desenvolvido por Goffman (2009) destaca essas características nas mais variadas representações que o sujeito faça de si. Nancy Baym (2010) comenta que no processo da comunicação mediada pelo computador há uma exigência de elementos comunicacionais que compensem a falta de "um corpo presente", como emoticons e outras linguagens específicas.

Assim, ao fazerem uso de uma gama de elementos simbólicos digitais, os usuários de tecnologias comunicacionais constituem identidades on-line, ou seja, os "espaços pessoais na web oferecem aos consumidores a oportunidade de construir colagens digitais usando símbolos e sinais para representar e expressar os seus autoconceitos" (Schau; Gilly, 2003, pp. 385-386).

Segundo Twenge e Campbell (2009), a construção de um perfil on-line passa por um processo de seleção minuciosa de elementos que informem e, principalmente, valorizem os aspectos positivos, construindo assim uma imagem mais atrativa de si. Os autores ainda consideram que, na internet, indivíduos têm a chance de encontrar certa audiência potencialmente desejada, de forma que, se pensarmos no caso estudado aqui, ao ressaltar o humor ácido de Katylene, Daniel alcançou uma considerável audiência, que resultou no status de "celebridade da web" que sua personagem adquiriu.

\section{Celebridades da web:}

\section{o perfil da personagem Katylene}

Paula Sibilia (2010) considera a superexposição/ espetacularização da intimidade dos sujeitos na internet semelhante a um outdoor, no qual, "o acesso à fama tem se democratizado" (2010, p. 53). No entanto, assim como Sá e Polivanov (2012) alertam, também compreendemos que tal perspectiva de entendimento das interações digitais é calcada numa observação baseada em um ponto de vista macro e homogeneíza as práticas e apropriações sociais em relação às tecnologias digitais da comunicação.

Contudo, apesar da liberdade de expressão e construção de identidades propiciadas pela internet e, mesmo a popularização de certas narrativas identitárias on-line, Primo (2009) delimita o efeito da "fama" de uma celebridade midiática a uma mínima relação com meios de comunicação massiva. Segundo o autor, "a emergência de celebridades a partir da blogosfera, por exemplo, depende da passagem desses blogueiros para programas e páginas da mídia de massa" (2009, p. 9). Portanto, mesmo que o autor admita que haja "emergência de novos líderes de opinião na web [...] em virtude da possibilidade de expressão e publicação de produtos culturais de forma independente" (2009, p. 10), a popularidade de alguém só passa a ser "fama" a partir de uma relação com meios massivos.
Rojek (2008), ao estudar a "cultura das celebridades", considera que a ação midiática de representação é o principio fundamental na instauração destas "mitologias", pois, enquanto construções socioculturais, "nenhuma celebridade adquire reconhecimento público sem a ajuda de intermediários culturais como diretores de cena da sua presença aos olhos do público" (Rojek, 2008, pp. 12-13). Assim, o fenômeno deve ser tratado enquanto uma representação e teatralização que deriva a "aura" em que são coroadas as celebridades. Além disso, o autor considera que o "mercado inevitavelmente transformou o rosto público da celebridade num bem de consumo" (Rojek, 2008, p. 16), ou seja, essa "aura" criada em torno de um sujeito transmuta-se em produto desejável, adquirindo assim uma poderosa função capitalista e mercadológica.

Retomando a questão da web, segundo Anderson (2006), a reputação alcançada por meio de um blog, para além dos ganhos diretamente relacionados ao mesmo (publicidade on-line e afins), pode ser transformada em outras formas rentáveis tal qual aconteceu com Katylene, que foi "comprada" pela MTV e ganhou um programa de TV. Daniel, enquanto criador da personagem, se utiliza do nome da mesma para trabalhar como DJ e foi colunista de celebridades do programa "Muito Mais".

Em seu estudo sobre "camgirls", Senft (2008) indica uma importante diferença entre os fãs de celebridades massivas e fãs do que ela chama de "micro-celebridade". Segundo a autora, o que mantém o vínculo com o público da web é o comprometimento da "celebridade", pois, ao considerarmos que não existe a mediação da mídia massiva, a reputação de tal sujeito se dá na conexão estabelecida entre "ce- 
lebridade" e fãs, em outras palavras, a "celebridade" não depende muito dos produtores dos meios de comunicação, pois é ela quem gera o próprio conteúdo. Portanto, não há nesta relação o desejo de saber detalhes sobre a vida pessoal da "celebridade".

Ao analisar a trajetória de Geisy Arruda, Lana (2013, p. 4) pondera que "o sucesso das celebridades pauta-se pela busca da fama através da mídia e da permanência no espaço da visibilidade" e que, neste ponto, a até então anônima estudante alçada à fama devido a um vídeo postado no Youtube (fato que leva a autora a considerar a mesma como uma "webcelebridade") tem conseguido manter-se em evidência, utilizando da internet como sua principal estratégia.

Já Liesenberg (2012), ao estudar a celebrificação da cantora de forró Stefhany do CrossFox, afirma que "a partir desta visibilidade mediada, operada hoje por quem tiver acesso à internet, sem depender da mídia massiva para essa mediação, muitos tornaram-se famosos na web, resultado da descentralização midiática que esses novos meios proporcionam". A autora comenta que, por constituir-se enquanto celebridade a partir da mobilização da audiência, a cantora inverte a direção do processo de surgimento de estrelas massivas, uma vez que percorre um trajeto de baixo para cima. Katylene também se encontra nesse mesmo polo de Stefhany.

\section{Seguidores e linguagem}

Ao pensarmos as relações estabelecidas entre o público e a "celebridade", é bastante produtivo o entendimento de Marshall (1997) da celebridade enquanto um signo, pois "a realidade material do signo da celebridade - isto é, a pessoa real que está no cerne da representação desaparece em uma formação cultural de significado" (Marshall, 1997, p. 57). Tal concepção é pertinente visto que tais relações se darão, em essência, semioticamente. O autor ainda caracteriza que essa formação cultural do significado ocorre em "uma área de negociação entre o público, a mídia, e a celebridade" (Marshall, 1997, p. 12), assim, ao perceber a celebridade enquanto um discurso que emerge em uma cadeia de significantes, a autoria de tal texto se divide entre as ações, por um lado, da mídia massiva, por outro, do público, sem esquecer da materialidade da "celebridade", ou seja, a celebridade-pessoa.

Pimentel (2005) compartilha da mesma opinião, pois, além de inserir a construção da celebridade em uma dimensão histórica e social, a autora aponta que o promotor desta construção é um coletivo. Desta forma, "a trama e a intriga da narrativa vão, assim, sendo alimentadas e tecidas junto com as revelações pessoais da própria 'celebridade', as opiniões do jornalista, do amigo e do inimigo, as estratégias comunicacionais e os flagrantes dos paparazzi" (Pimentel, 2005, p. 196). Não obstante, ela ainda garante um papel preponderante e imprescindível no que ela caracteriza como "avaliação do 'eu-personagem' e seu enquadramento em padrões de reconhecimento" (Pimentel, 2005, p. 196).

No entanto, mesmo que haja uma importante participação do público na conformação da "celebridade", esta relação se estabelece apenas com a representação, o que não significa que ela não exista, pois "seus efeitos na organização de emoções e estilo de vida do fã são reais" (Rojek, 2008, p. 73). Rojek ainda acrescenta que são estabelecidas "relações de intimidade construídas através da mídia, e não pela experiência direta e encontros cara a cara" (2008, p. 58).

De certa forma, as considerações de Rojek entram em consonância com o trabalho desenvolvido por Shirky (2008) que considera que existam duas condições primordiais pra que haja "fama", sendo elas a grande audiência mantida e a incapacidade de corresponder. Inegavelmente, existe entre as duas um forte vínculo, uma vez que, devido ao tamanho da audiência, a resposta é limitada a uma parte dela.

Para Pimentel (2005), a questão referente à comunicação (ou não) entre público e celebridade, se configura como um processo de reconhecimento do público naquela imagem construída coletivamente. Para o autor, a celebridade é "um personagem das narrativas midiáticas" gera padrões de reconhecimento ou imagens "que funcionam como referência para aqueles que se reconhecem nelas" (Pimentel, 2005, p. 200).

Podemos pensar que essa identificação se converte em "consumo da celebridade", uma vez que "o consumo tem uma dimensão simbólica e cultural e, portanto, comunicativa, uma vez que nos revela como os sujeitos sentem, pensam e se organizam, propiciando-lhes ao mesmo tempo material para a construção de suas próprias micronarrativas" (Sá; Polivanov, 2012, p. 8). Portanto, a identificação com determinada celebridade e, consequente, consumo da mesma enquanto bem cultural trata-se de um processo produtor de identidades. Ou seja, nesse processo, os sujeitos apropriam-se de elementos que remetem ou mesmo originem-se do signo-celebridade de forma a utilizar-se de seu potencial semiótico para um processo de expressão identitária.

A partir deste ponto de vista, determinadas "personagens da narrativa midiática", tal qual Katylene, carregam em si uma carga cultural que culmina em um contexto cultural próprio. Isso, aliado ao aumento crescente das funções de linguagem nas redes sociais, permitiu que a personagem se desenvolvesse com uma linguagem bem característica e marcada por gírias da subcultura gay e trocadilhos (como exemplificado no início do texto). 
Assim, entre o público consumidor da personagem, tanto no blog, quanto no Twitter, há uma hibridização das diferentes linguagens e competências de leitura midiática:

Há um aprendizado e uma cognição específicas que devem ser potencializadas e apreendidas e, por outro lado, percebemos apropriações criativas que só fazem sentido dentro de um determinado contexto e que trabalham com níveis diferentes de intertextualidades e referências que só podem ser compreendidas na imersão e na vivência cotidiana de tais dinâmicas: o conhecimento arqueológico dos memes, dos virais, das gírias e até mesmo das funcionalidades e ferramentas funcionam como moeda de disputa do capital social dos usuários mais familiarizados com os menos familiarizados (Amaral, 2011, on-line).

Na tentativa de esclarecer, desmembrar tal complexificação e delinear essa a relação estabelecida entre Katylene enquanto "celebridade" e sua audiência, na próxima seção fazem-se considerações sobre as interações ocorridas entre os dias 28 de abril e 4 de maio de 2012, em função da efeméride da data de aniversário de Daniel Carvalho, criador da personagem Katylene, no dia $1^{\circ}$ de Maio desse mesmo ano.

\section{Apontamentos sobre o \#KatyBDay}

Apesar da personagem Katylene utilizar diversas plataformas disponíveis on-line (Blog, Orkut, Facebook, Twitter, Flickr e Youtube) e do blog ser o principal meio de expressão de conteúdo, o Twitter (Figura 1) é bastante ativo e possui um grande número de conversações com os seguidores, sendo então a segunda ferramen- ta on-line mais utilizada pela personagem e o objeto abordado pelo presente artigo a partir de um episódio específico no qual localizamos conversações.

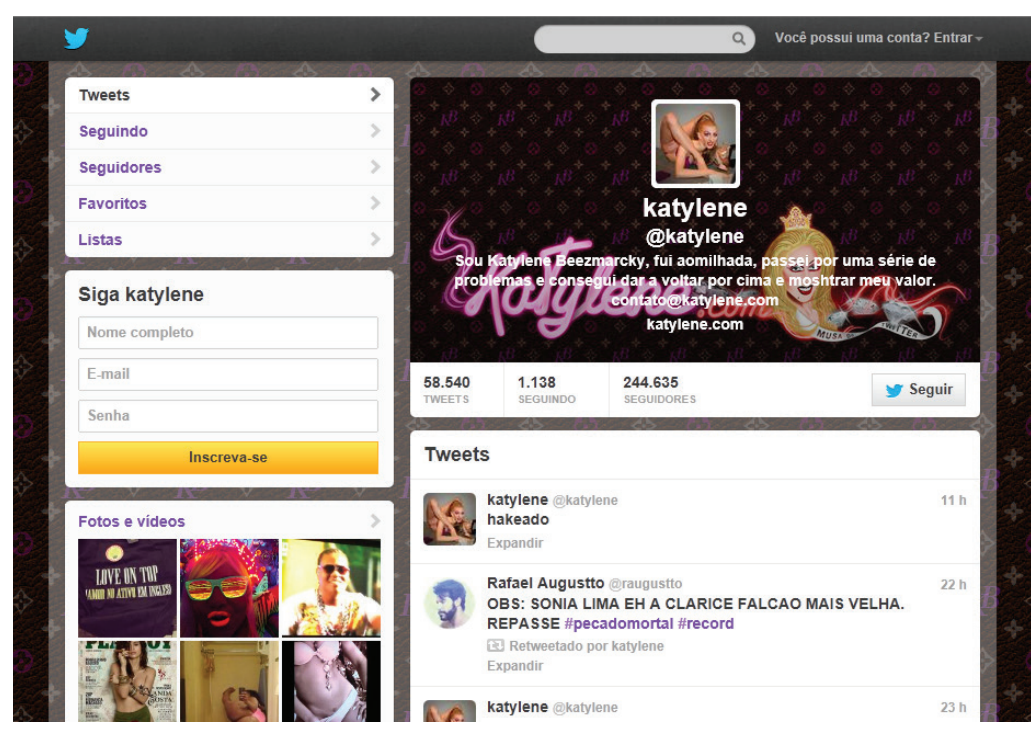

Figura 1: Print do Twitter @katylene

A biografia inicial da página reflete a mesma narrativa disponibilizada no blog sobre a travesti que "cresceu em meio a giletadas, apedrejamentos e muita mágoa e que, hoje, tem carreira de consultora estética". Um dos pontos de convergência dessas narrativas é a presença da violência como constituinte de uma "cultura travesti", até mesmo as "giletadas" estão intimamente ligadas à situação de marginalidade à qual muitas travestis estão expostas. Os tweets também refletem em grande parte o mesmo estilo das postagens do blog (conforme a Figura 2), pois, o blog Katylene.com (e consequentemente, o Twitter da personagem) não é apenas mais um site de fofoca, mas, através de elementos textuais/gráficos, ele veicula uma espécie de cultura/estética "Katylênica". Tal cultura será marcada por um modo específico de escrita e conteúdo abordado, em grande parte te- mas oriundos da cultura pop como celebridades, novelas, modelos, atores e atrizes, etc.

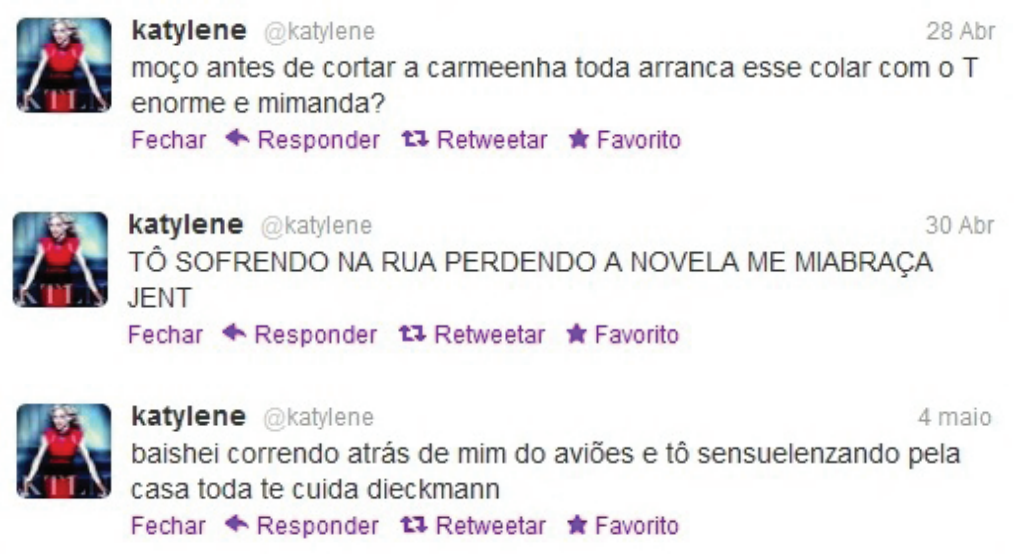

Figura 2: Exemplos de Tweets

Graficamente, o plano de fundo utilizado no Twitter é o mesmo no blog, marrom com um padrão que intercala as iniciais "KB" em lilás e outro detalhe que lembra uma pequena flor em bege. Já as imagens utilizadas no perfil variam com o passar do tempo, mas, como pode ser percebido na figura 1, comumente as imagens têm alguma referência "pop". No caso do exemplo, a imagem é uma montagem da foto de capa do CD "MDNA" (versão standard) da cantora Madonna.

Em muitos tweets, tanto de Katylene, quanto dos seus seguidores, a narrativa que "une" a identidade do criador e da personagem em uma só (Katylene) está presente - como pode ser visto nos tweets em que ela afirma que será $D J$ em alguma festa ou quando alguém se refere a algo que Daniel tenha feito (como fez o usuário Gui Barros). No entanto, a ocasião do aniversário fez com que alguns seguidores se perguntassem sobre quem era o aniversariante, Daniel ou Katylene, como no tweet de Douglas Ribas. Além disso, no diálogo entre a personagem e Adriane Galisteu, a apresentadora pergunta sobre 
o blogueiro e Katylene responde em terceira pessoa, realizando um movimento de separação entre os dois.

katylene @katylene

(28 Abr

TWSP! vai lá comigo ralar a xana no asfalto!!!!!!! Fechar $\$$ Responder 27 Retweetar $\star$ Favorito

Gui Barros @GuiBarrosP

CHOCADO! O bofe da empregada é melhor que o professor de filosofia que a @katylene pegou na "LeLe"! Expandir

(2)

Douglas Ribas $\dagger$ CadeODoug andir @cadeodaniel ? Expandir

@GalisteuOficial brigada, patroa! daniel já ta bêbado e com saudadyyyssssssss

- Esconder conversa $\ll$ Responder $\quad$ t7 Retweetar $\star$ Favorito

Figura 3: Tweets sobre Katylene e Daniel

O fato de o blog ter se popularizado e ter alcançado determinado renome resultou numa inserção de Katylene em uma espécie de "star system" do cenário brasileiro na internet. Durante o tempo em que suas interações no Twitter foram observadas, foi possível perceber que ela se relaciona de forma próxima com outros tweeteiros/blogueiros de igual popularidade tal qual Hugo Gloss (@hugogloss) e Nilson Xavier (@ nilsonxavier). Contudo, o fato de Daniel/Katylene ter ultrapassado a barreira da internet para a grande mídia - a personagem foi notícia em vários portais e revistas e, como dito anteriormente, Daniel foi colunista no programa de Adriane Galisteu - faz com que suas relações não sejam estabelecidas apenas com personalidades da internet, mas também de outras áreas como a Miss Brasil 2013, Priscila Machado, e a atriz Suzana Pires.

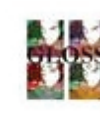

Hugo Gloss o hugooloss

Pra dyva twitteira e blogayra desse mundo: @katylene! (udeodaniel brilhem mto e ganhem mtas neca odara nesse 노 Retweetado por katylen

Favorito

\section{Nilson Xavi} @katylene Parabéinsh pelo nyvver, Katchylene

12.

Priscila Machado@priscilamachato Aniver da @katylene !!! A trava/boy mais magia do M'Boi!!! chuva de necaaa!!! 넌 Retweetado por katyler Fechar $\star$ Responder 27 Retweetar $\star$ Favorito

SUZANA PIRES

@katylene

Qkatylene congrats Katyyyy!!

Figura 4: Tweets de "celebridades"

Tanto nos tweets de "celebridades", quanto nos tweets dos seguidores "comuns", um aspecto que se mostra constantemente em apropriação e uso é a linguagem característica da personagem. A grande influência do pajubá10 e os trocadilhos e grafias diferenciadas - que imitam a fonética das palavras - funcionam como uma dinâmica específica neste contexto "amadrinhado" pela personagem. $O$ terceiro exemplo trazido na figura 5, mostra como aqueles que não estão familiarizados com a linguagem têm problemas de compreensão daquilo que é dialogado nesse cenário específico.

Sr. Barros @senhorbarros $30 \mathrm{~A}$

Eeriado e sm pelo NIVER da KATY a mais linda du ou... Nă \#katybday

Baretado por katylene

Eetweetar « Favorito

(6)

Iuciano

não vai rolar um \#pirocaday em homenagem a sofisticadissima blogueira travesti @katylene? Expandir

:

Felipe Barahona @elipeBarahona

$1 \mathrm{mat}$

@katylene nao entendo nada do que vcs falam, mas parabens!!

Ev Retweetado por katylene

Figura 5: Tweets de Seguidores "comuns"

A partir da observação do perfil de Katylene no Twitter, percebe-se uma série de fatores a serem discutidos em relação à construção de uma identidade on-line e sua relação com os seguidores. A origem de personagens como Katylene demonstram como a internet e suas especificidades, geram um espaço para além de simplesmente propiciar a criação e manipulação de uma identidade basicamente desprovida de referentes do sujeito off-line, também permite que esse desenvolvimento acarrete na conformação de uma cultura veiculada por tal identidade. Assim, ao estabelecer relações sociais em torno do contexto da produção de conteúdo e, consequentemente, uma cultura própria, o "signo-celebridade" de Katylene interage com um grupo social com uma característica dinâmica. Apesar de existir o vínculo "Daniel Carvalho, o criador de Katylene", ambos coabitam os mesmos sites de redes sociais constituindo uma narrativa que nunca dissolve por completo o vínculo en- 
tre criador e criatura, permanecendo num eterno ir e vir entre quem é Daniel e quem é Katylene e, principalmente, entre a fusão dos dois em uma pessoa e a cisão em duas.

\section{Considerações finais}

O presente trabalho buscou observar um caso específico dentro do perfil do Twitter da personagem Katylene para discutir tais questões de ordem identitária. Partimos da discussão sobre as possibilidades de instituições de narrativas on-line de si para analisarmos o "embaralhamento" de apropriações de linguagem como rastros de representação identitária entre a personagem Katylene e seu criador Daniel, tendo como exemplo as conversações entre seus seguidores em torno da data do aniversário de Daniel em 2012. Assim, observou-se como a apropriação criativa e as práticas culturais em torno das plataformas tecnológicas configuram um espaço alternativo para a popularização de culturas e mesmo conformação em relação a um diferente "star system"11.

Percebeu-se que "nascida" do blog, a personagem permanece vinculada a ele mesmo que em outros espaços, até mesmo porque sua narrativa de si é construída de maneira que forma uma rede de informações difundas pelas diferentes plataformas. Em relação ao questionamento inicial sobre o paralelismo entre as identidades de Daniel e Katylene, verificou-se que, por mais que as falas da personagem tentem distanciar criador e criação, no momento em que Daniel Carvalho deixa de ser um simples estudante de moda, para ser o sujeito por trás de Katylene, o vínculo estabelecido como "Daniel é criador de Katylene" torna-se quase que inevitável. Assim há a hibridização entre ambos, potencializada pelos usos da linguagem na conversação entre os diferentes perfis e seus seguidores.

Além disso, a popularização do blog e as consequentes aparições na TV ocasionaram a constituição de um processo de celebrificação e fama para ambos. Tanto Katylene, quanto Daniel, passaram a integrar o time de "webcelebridades" e a serem reconhecidos. A partir das interações estabelecidas no período observado, fica explicitado que Daniel/Katylene possui relações de proximidade com famosos, o que demonstra ter acesso a esse grupo social.

A apropriação criativa da materialidade do meio e da linguagem, feita por Daniel, enquanto ferramenta à expressão/movimento de traços culturais diversos pode ser indicada como um dos elementos determinantes que se possibilitou a emergência de Katylene enquanto um ponto convergente entre a subcultura gay e outras audiências maiores, de forma que a linguagem da personagem e seus bordões se torna uma marca e configura uma possível "cultura de Katylene e seus seguidores" que é replicada, retweetada, compartilhada e utilizada em vários outros contextos e ambientes.

Um dos componentes mais importantes dessa cultura é a linguagem criada da convergência do pajubá das ruas de prostituição e emulações das formas vocais da palavra. Atualmente, o pajubá não é mais restrito e já se propaga para além da subcultura gay, uma vez que cada vez mais personagens gays surgem nas novelas e filmes falando "gírias gays" que caem no gosto popular. Inclusive, durante a exibição da novela Insensato Coração (Rede Globo, Gilberto Braga e Ricardo Linhares), Daniel Carvalho ajudou a Deborah Secco a compor sua personagem "Natalie Lamour" que utilizava muitas gírias da personagem ${ }^{12}$. Além disso, na relação estabelecida entre a perso- nagem e seus seguidores é possível perceber que a linguagem tem um papel fundamental. A linguagem utilizada torna-se uma espécie de moeda na dinâmica cultural desenvolvida no grupo constituído por "Katylene e seus seguidores". Assim, qualquer pessoa alheia que se arrisque a uma primeira inserção nesse contexto, ou seja, alguém que se propõe entender a comunicação necessitará realizar um investimento no sentindo de apreender esse "idioma nativo".

Outro ponto de destaque diz respeito à importância dos seguidores na legitimação da personagem. Em grande parte (senão em sua totalidade), a fama na internet depende da relação entre "celebridade" e público, essencialmente, por não conter o elemento "mídia massiva". No caso de Daniel/Katylene, a partir da fama alcançada sem o "midiático", foi possível sua inserção na narrativa midiática com o programa de Katylene na MTV e a contratação de Daniel para o programa de Adriane Galisteu.

Por fim, é necessário compreender que mesmo que determinada tecnologia seja criada com uma finalidade específica, as práticas sociais e apropriações dos sujeitos não esgotam as potencialidades das mesmas. Assim, observar a performance de Katylene no Twitter nos mostra uma série de fatores relacionados ao uso dessa plataforma. Entretanto, nossa observação contempla os aspectos relativos à identidade e à linguagem, nesse caso específico, restando ainda muito a ser revelado por pesquisas posteriores.

\section{Referências}

AMARAL, A. Redes sociais, linguagem e disputas simbólicas. ComCiência, Universidade Estadual de Campinas, Campinas, 2011. Disponível em: <http://goo.gl/UostlO>. Acesso em: 26 dez. 2011. 
ANDERSON, C. A cauda longa: do mercado de massa para o mercado de nicho. Rio de Janeiro: Elsevier, 2006.

BAYM, N. Personal Connections in the Digital Age. Cambridge: Polity Press, 2010.

DONATH, J. S. Identity and deception in the virtual community. In: KOLLOCK, P.; SMITH, M. (org.). Communities in cyberspace. Londres: Routledge, 1999.

DÖRING, N. Personal home pages on the web: a review of research. In: Journal of Computer-Mediated Comunicaction, n. 7, v. 3, 2002. Disponível em: <http://migre. me/9gVHd>. Acesso em: 12 abr. 2012.

GIDDENS, A. Modernidade e identidade. Rio de Janeiro: Jorge Zahar, 2002.

GOFFMAN, E. A representação do eu na vida cotidiana. Petrópolis: Vozes, 2009.

KENWAY, J. Educando cybercidadãos que sejam "ligados" e críticos. In: SILVA, L. H. (org.). A escola cidadã no contexto da globalização. Petrópolis: Vozes, 1998. p. 99-120.

KRAMBECK, Rafael. Cyberqueer: Performances de Gênero e Mobilização de Traços Identitários na Construção da Narrativa da Personagem Katylene no Blog e no Twitter. 2013. 111 f. Dissertação (Mestrado em Ciências da Comunicação) - Faculdade de Comunicação, Unisinos, 2013.

LANA, L. A mulher bem-sucedida e a participação da internet na construção de celebridades femininas.
In: CONGRESSO BRASILEIRO DE CIÊNCIAS DA COMUNICAÇÃO, 36., 2013. Manaus. Anais eletrônicos... Manaus: Sociedade Brasileira de Estudos Interdisciplinares em Comunicação (INTERCOM), 2013. Disponível em: <http://www.intercom.org.br/papers/nacionais/2013/resumos/R8-1664-1.pdf >. Acesso em: 29 set. 2013.

LIESENBERG, S. O processo de celebrificação na internet: o caso de Stefhany do CrossFox. 2012. 279 f. Dissertação de Mestrado (Mestrado em Comunicação e Informação) - Programa de Pós-Graduação em Comunicação e Informação (PPGCOM), Universidade Federal do Rio Grande do Sul (UFRGS), Porto Alegre, RS, 2012

MARSHALL, P. D. Celebrity and power. Minneapolis: University of Minneapolis Press, 1997.

MOORE, H. Fantasias de poder e fantasias de identidade: gênero, raça e violência. Cadernos Pagu, Universidade Estadual de Campinas, Campinas, v. 14, 2000, p. 13-44.

MORIN, E. As estrelas. Mito e sedução no cinema. Rio de Janeiro: José Olympio, 1989

PIMENTEL, M. C. A construção da celebridade midiática. Contemporânea, Universidade do Estado do Rio de Janeiro, Rio de Janeiro, v. 3, n. 4, 2005, p. 193-203.

PRIMO, Alex. Existem celebridades da e na blogosfera: reputação e renome em blogs. In: Líbero, São Paulo, v. 12, n. 24, p. 107-116, dez. de 2009.
RECUERO, R. Redes sociais na internet. Porto Alegre: Sulina, 2009.

ROJEK, C. Celebridade. Rio de Janeiro: Rocco, 2008.

SÁ, S.; POLIVANOV, B. B. Materialidades da comunicação e presentificação do sujeito em sites de redes sociais. In: ENCONTRO ANUAL DA COMPÓS, 21., 2012. Juiz de Fora. Anais eletrônicos... Juiz de Fora: Associação Nacional dos Programas de Pós-Graduação em Comunicação (COMPÓS), 2012.

SCHAU, H.; GILLY, M. We Are What We Post? Self-Presentation in Personal Web Space. Journal of Consumer Research, Inc., vol. 30, 2003.

SENFT, T. M. Camgirls: celebrity \& community in the age of social networks. New York: Peter Lang, 2008.

SHIRKY, C. Here comes everybody: how digital networks transform our ability to gather and cooperate. New York: Penguin Press, 2008.

SIBILIA, P. $O$ show do eu. A intimidade como espetáculo. Rio de Janeiro: Nova Fronteira, 2008.

TURKLE, S. A vida no ecrã: a identidade na era da internet. Lisboa: Relógio D'água, 1997.

TWENGE, J. M.; CAMPBELL, W. K. The narcissism epidemic: living in the age of entitlement. New York: Free Press, 2009.

VIP, Ângelo; LIB, Fred. Aurélia, a Dicionária da Língua Afiada. Editora do Bispo: São Paulo, 2006. 
“Uma festa baphônica no Twitter": narrativa de si e apropriação de linguagem [...]

\section{Notas}

1 Doutora em Comunicação Social pela Pontifícia Universidade Católica do Rio Grande do Sul (PUCRS). Professora do Programa de Pós-Graduação em Ciências da Comunicação da Universidade do Vale do Rio dos Sinos (UNISINOS - Av. Unisinos, 950, Santo Inácio, CEP: 93022-000, São Leopoldo/RS - Brasil). E-mail: adriana.amaral08@gmail.com.

2 Mestre em Ciências da Comunicação pela Universidade do Vale do Rio dos Sinos (UNISINOS - Av. Unisinos, 950, Santo Inácio, CEP: 93022-000, São Leopoldo/RS Brasil).E-mail: krambeckrs@gmail.com.

3 Biografia de Katylene disponível no Blog.

4 Disponível em <http://katylene.com>. Acesso em 10 out. 2012.

5 Disponível em: <http://papelpop.com/>. Acesso em 15 nov. 2012.

6 Disponível em: <http://queridoleitor6.zip.net/ arch2007-08-26_2007-09-01.html\#2007_0830_12_18_47-2561397-0> . Acesso em 05 jun. 2012.

7 Disponível em: <http://drispaca.blogspot.com. br/2007/08/bom-todo-mundo-sabe-que-eu-leio-o-papel.html>. Acesso em 05 jun. 2012.

8 Disponível em: <http://twitter.com/katylene>. Acesso em 02 fev. 2013.

9 O presente artigo é um desdobramento de uma parte da dissertação "Cyberqueer: Performances de Gênero e Mobilização de Traços Identitários na Construção da Narrativa da Personagem Katylene no Blog e no Twitter" defendida por Rafael Krambeck no PPGCCOM da UNISINOS em 2013.

10 Baseada nas línguas africanas empregadas pelo candomblé, é a linguagem praticada inicialmente pelos travestis e posteriormente estendida a todo universo gay. Variante: bajubá (Vip; Lib, 2006).

11 Contudo, se concordarmos com a perspectiva de Morin (1989), podemos pensar que "celebridades" são quaisquer atores sociais que podem (e o fazem) explorar sua notoriedade para garantir benefícios. Além disso, a admiração e identificação por seus fãs é o principal elemento que legitima o status de celebridade.

12 Ver em: <http://br.omg.yahoo.com/blogs/pronto-falei/twitteiros-famosos-ajudaram-deborah-secco-compor-natalie-lamour-125707364.html>. Acesso em 03 fev. 2013. 